\title{
Chemical Synthesis and Functionalization of Cobalt Ferrite Nanoparticles with Oleic Acid and Citric Acid Encapsulation
}

\author{
Shrikant C Watawe ${ }^{1, a}$ and B P Ladgaonkar ${ }^{2}$ \\ P D Karkhanis college Ambarnath, Dist - Thane, Maharashtra 421501 INDIA \\ Shankarrao Mohite Mahavidyalaya, Akjuj, Dist- Solapur Maharashtra INDIA
}

\begin{abstract}
The functionalized nanoparticles have now a prime importance because of their wide ranging biomedical applications. The particles having size range $30 \mathrm{~nm}-150 \mathrm{~nm}$ are useful for cell wall interaction specifically the pinocytosis which takes place in all types of cells. The Cobalt ferrite nanoparticles have been synthesized using chemical co- precipitation route and the $\mathrm{pH}$ and temperature of the synthesis is controlled to obtain the optimum sized particles. The coating of Sodium Oleate and Citric acid was carried out in aqueous medium at room temperature. The characterization of coated and uncoated particles has been carried out using XRD and IR which confirm the ferrite structure formation. The TGA-DTA analysis shows the coating of magnetic particles. The SEM micrographs reveal the particle size, before and after coating to be in the range of 45 to $90 \mathrm{~nm}$. The saturation magnetization is found to be $16.8 \mathrm{emu} / \mathrm{gm}$.
\end{abstract}

\section{Introduction}

The work on functionalized biocompatible magnetic nanoparticles is of prime importance from biomedical applications such as cell separation, targeted drug delivery, therapeutical applications etc. [1-4]. The cobalt ferrites synthesized using the standard double sintering technique have been reported by many researchers [5,6], but the chemical synthesis route has an advantage on controlling the particle size. The wet chemical co-precipitation at neutral $\mathrm{pH}$ results in suitable particle size range and with sufficient magnetic properties necessary for their biocompatible applications. The size range as reported by Tobias Neuberger et al.[7], is sensitive in phagocytosis and pinocytosis therefore it is required to maintain the particle size range between $30 \mathrm{~nm}$ to $150 \mathrm{~nm}$, which is suitable for pinocytosis, a process which takes place in all types of cells[7]. The toxicity of the magnetic materials is critical therefore suitable coating material is required to encapsulate the nanoparticles and also to maintain the size of the coated particle in the suitable range. In the present communication the Oleic acid has been used as a coating material since it has carboxyl functional group to immobilize ligonucleoides, proteins and anti-cancer drugs on particle surfaces.[8-9], but the methyl group may be mildly toxic. Therefore the Cobalt ferrite particles have also been coated with citric acid which is anti- oxidant, important intermediate of citrate cycle, found in metabolism of all organisms, having non- toxic hydroxyl group which may be used as a drug carrier.

\section{Experimental}

The cobalt ferrite particles were synthesized using alkaline co-precipitation method using AR grade metal chlorides as starting agents. The stoichometric proportions of $\mathrm{FeCl}_{3}$ and $\mathrm{CoCl}_{2}$ were mixed in 100 $\mathrm{ml}$ deionised water and kept under constant stirring in a magnetic stirrer at $25^{\circ} \mathrm{C}$ while $1.5 \mathrm{M} \mathrm{NaOH}$ was added drop by drop up to completion of reaction. The precipitate was washed with deionised water to remove excess $\mathrm{NaOH}$ and dried in desiccators to obtain Cobalt ferrite particles. Yin et al. [9] have used Oleic acid as the starting material for coating but in the present communication oleic acid was neutralized using $\mathrm{NaOH}$ to obtain the salt of sodium Oleate which was then mixed in deionised water at neutral $\mathrm{pH}$. This is useful to control coating thickness. Ferrite particles were added in this solution at vigorous stirring, at $90^{\circ} \mathrm{C}$ for 30 minutes so as to coat the ferrite particles. The coated particles were then washed to remove excess coating and centrifuged in water. The upper layer was used to collect the smaller sized

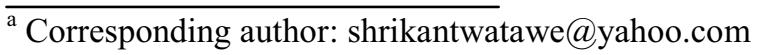


particles. A solution of $0.05 \mathrm{M}$ citric acid was prepared by dissolving AR grade solid citric acid particles in deionised water, the $\mathrm{pH}$ was maintained at 4.5. The ferrite particles were then mixed in the solution and continuously stirred for 30 minutes to obtain the citrate coated cobalt ferrite nanoparticles. The characterization was carried out using PHILIPS (PW3710) X-ray diffractometer with $\mathrm{Cu}$ $\mathrm{K} \alpha$ radiation ( $\lambda=1.5424$ A.U.) in the $\theta$ range $20^{\circ}$ to $80^{\circ}$. The IR spectrographs were carried out on SHIMADZU (FTIR - 8400s) spectrometer in the wave length range $400 \mathrm{~cm}^{-1}$ to $2000 \mathrm{~cm}^{-1}$. The SEM micrographs were taken on JEOL-JEM-6360 microscope. The TGA/DTA measurements were carried out using UNIVERSAL V2 4F TA instrument in the Nitrogen atmosphere at the rate $10^{\circ} \mathrm{C} / \mathrm{min}$. The PC coupled Hysteresis loop tracer was used for measurement of saturation magnetization.

\section{Results and Discussion}

The X-ray diffraction pattern [Fig. 1] of the synthesized final product, $\mathrm{CoFe}_{2} \mathrm{O} 4$ is with the expected inverse spinel structure with no other phase/impurity. The particle size was obtained by using Scherer's formula using first two strongest XRD peaks. The average size is found to be $45 \mathrm{~nm}$ which may be attributed to the reaction being carried out at room temperature and maintaining the $\mathrm{pH}$ at or below 7.0. The lattice parameter obtained using the XRD data is found to be 8.32 A.U. which is in agreement with the reported values $[8,10]$. The X-ray diffraction pattern obtained for the Oleate and citrate coated Cobalt ferrite is shown in Fig. 2 and 3. The coated ferrite particles show the conventional X-ray diffraction as the coating being polymer, non-crystalline material dose not introduce additional peaks or affect the original pattern. Similar results for Oleic acid coated Nickel ferrite has been reported by H.Yen et al. [9]

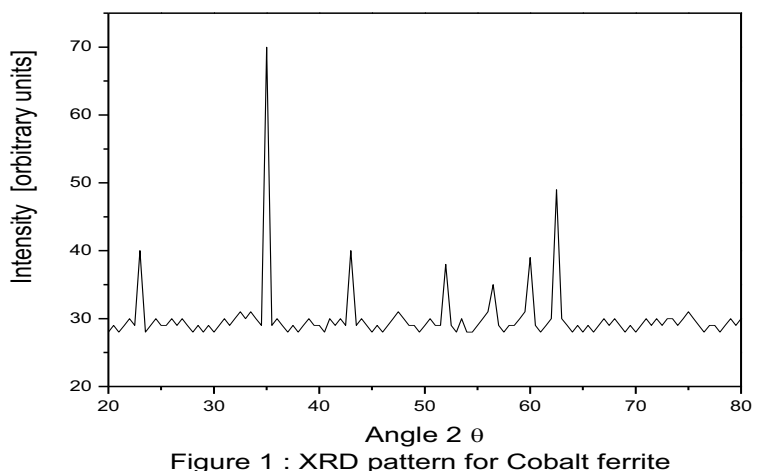



Figure 2: XRD pattern for Oleate coated Cobalt Ferrite



Fig 3.: XRD pattern for Citrate coated Cobalt ferrite

In the natural spinel $\left(\mathrm{MgAl}_{2} \mathrm{O} 4\right)$ form with space group $7 \mathrm{Fd} 3 \mathrm{~m}-\left(\mathrm{Oh}^{7}\right)$, Waldron [11] has attributed the $v_{1}$ band to the intrinsic vibrations of tetrahedral group $\left(\approx 600 \mathrm{~cm}^{-1}\right)$ and $v_{2}$ to octahedral group $\left(\approx 400 \mathrm{~cm}^{-1}\right)$. The IR spectrum of the Cobalt ferrite particles is shown in Fig. 4. The absorption bands observed at $430 \mathrm{~cm}^{-1}$ and $570 \mathrm{~cm}^{-1}$, may be attributed to the octahedral and tetrahedral intrinsic vibrations respectively. The graph dose not shows the splitting indicating negligible formation of $\mathrm{Fe}^{2+}$ ions, which must be taken care of during the synthesis of Cobalt ferrites. The co- precipitation method could be responsible for this effect. Similar results have also been reported by Watawe et al [12]. The IR spectra for Oleate and citrate coated cobalt ferrite particles are shown in Fig. 5 and 6 respectively. The Oleate coated sample shows peaks at $1412 \mathrm{~cm}^{-1}$ due to $\mathrm{C}-\mathrm{H}$ bending vibrations, $1553 \mathrm{~cm}^{-1}$ to the $\mathrm{C}=\mathrm{O}$ group in carboxylate salt, $2853 \mathrm{~cm}^{-1}$ to the $-\mathrm{CH} 2$ symmetric stretch and $2924 \mathrm{~cm}^{-1}$ asymmetric stretching vibration for $-\mathrm{CH} 2$. The peaks $3400 \mathrm{~cm}^{-1}, 2926$ $\mathrm{cm}^{-1}, 2853 \mathrm{~cm}^{-1}, 1553 \mathrm{~cm}^{-1}, 1412 \mathrm{~cm}^{-1}$ and 692 $\mathrm{cm}^{-1}$ which may be attributed to the vibrations of bonds of Oleate. The citrate coated sample shows peaks at $3410 \mathrm{~cm}^{-1}$ due to $-\mathrm{OH}$ stretching, $3000 \mathrm{~cm}^{-1}$ for $-\mathrm{CH}$ stretching, $1553 \mathrm{~cm}^{-1}$ for carbonyl group stretching, and $1412 \mathrm{~cm}^{-1}$ for $-\mathrm{CH}_{2}$ bending vibrations The peaks have been attributed to 
the vibrations in accordance with the correlation chart for organic molecules [13]. The peaks at $570 \mathrm{~cm}-1$ and $480 \mathrm{~cm}-1$ have been observed along with the above peaks which are in accordance with the values reported for Cobalt ferrite samples. The SEM micrographs of the cobalt ferrite nanoparticles, Oleate coated cobalt ferrite and citrate coated cobalt ferrite nanoparticles are depicted in Fig 7, 8 and 9 respectively. The particle size has been estimated using the conventional line intercept method. The particle size for uncoated cobalt ferrite is found to be $45 \mathrm{~nm}, 60$ $\mathrm{nm}$ for Oleate coated particles and $70 \mathrm{~nm}$ for citrate coated cobalt ferrite nanoparticles. The particle size obtained is as a result of the co-precipitation method, maintaining the $\mathrm{pH}$ at or below 7.0 and the temperature of synthesis i.e. room temperature. PetriFunk et.al [3] have reported on the effect of $\mathrm{pH}$ and temperature of synthesis on the particle size. The basic $\mathrm{pH}$ for synthesis and higher temperature increases the particle size. Hence maintaining the $\mathrm{pH}$ and temperature was crucial in the present case. A.S.Eggemann et.al. [14] have reported regarding suitable particle size range for in vivo applications from pinocytosis point of view. The particle size obtained in the present case is in the required range. The particle size shows an increase after coating which is as expected.

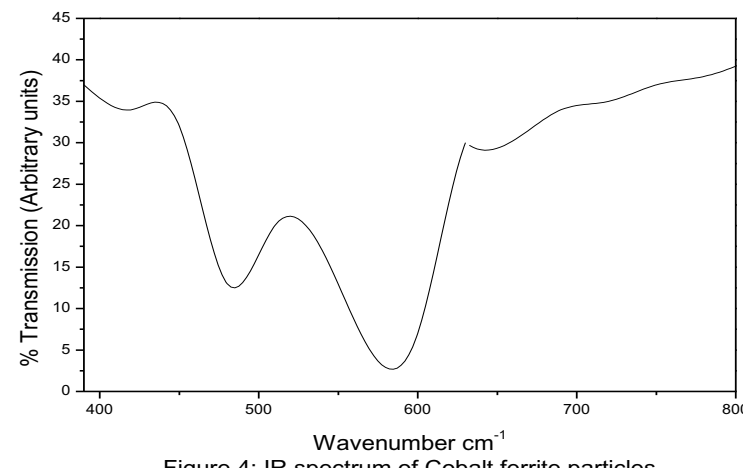

Figure 4: IR spectrum of Cobalt ferrite particles

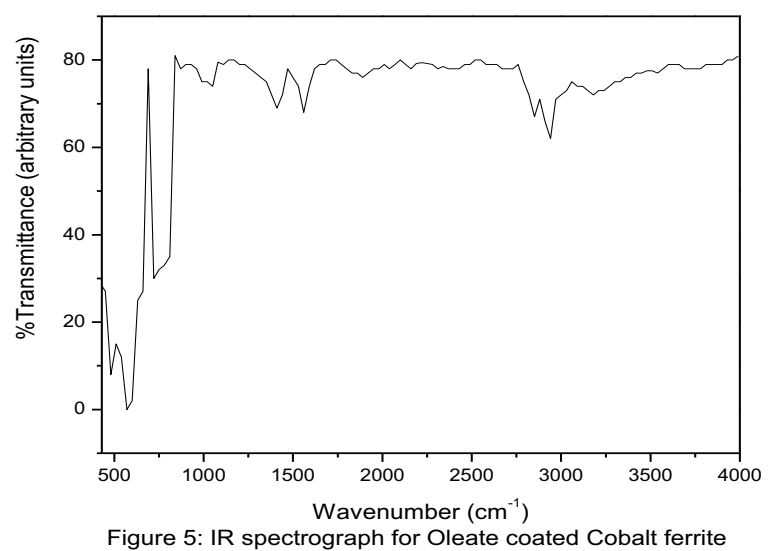

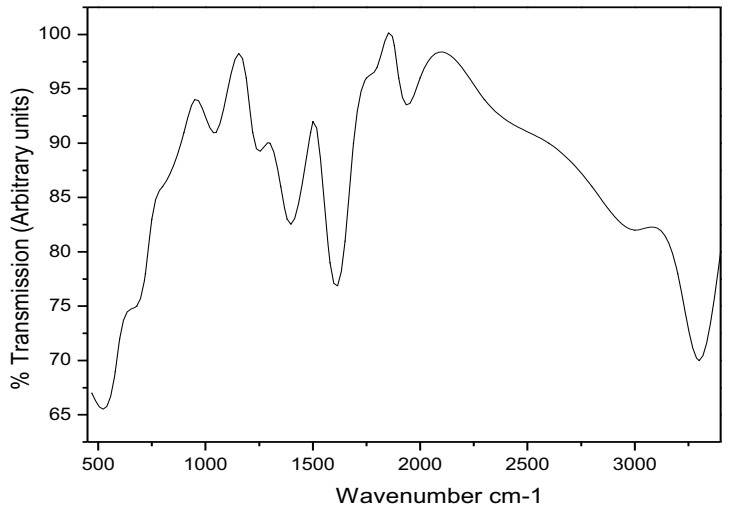

Figure.6. IR spectrogram for Citrate coated Cobalt ferrite particles

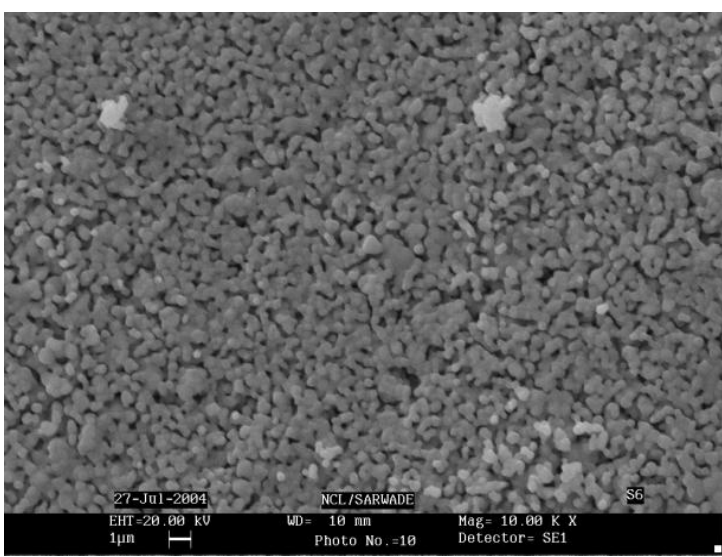

Fig 7. SEM Micrographs for cobalt Ferrite

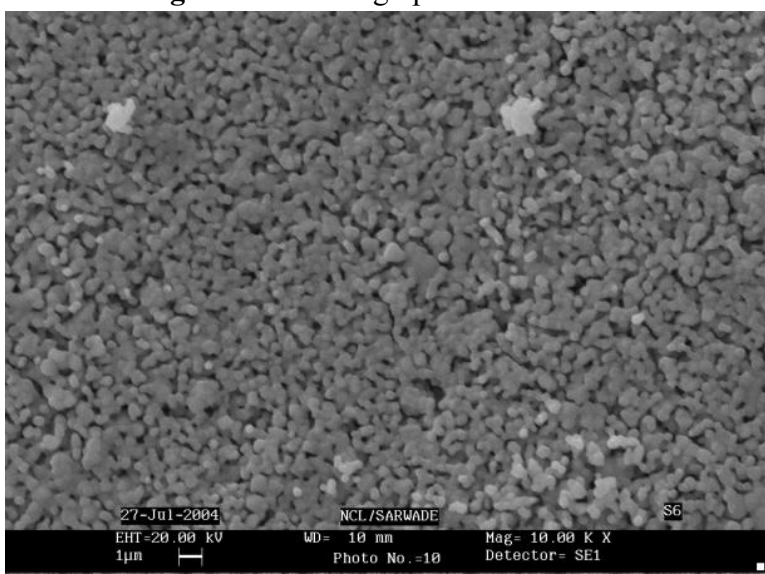

Fig 8. Sem Micrographs for Oleate coated cobalt ferrite

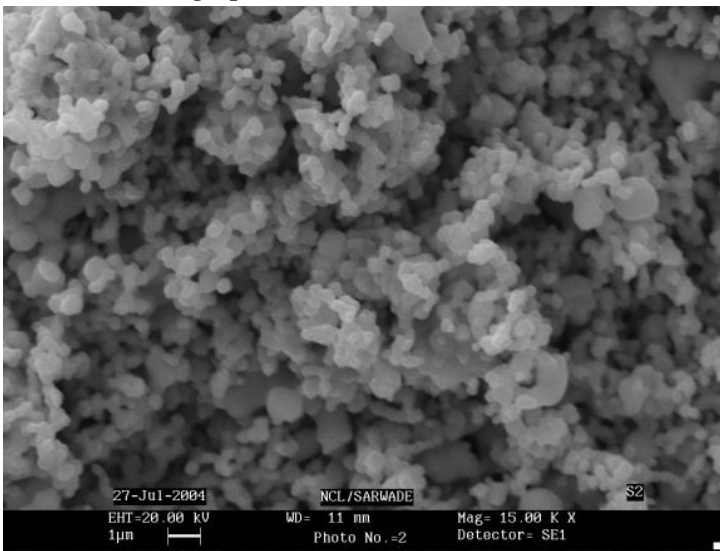

Fig 9. SEM Micrographs for Citrate coated cobalt ferrites 
The saturation magnetization for the uncoated and coated samples depicted in Table 1 are found to be 16.8 $\mathrm{emu} / \mathrm{gm}$ and 9.8 and $9.0 \mathrm{emu} / \mathrm{gm}$ respectively. The reduction in $\mathrm{Ms}$ is attributed to the \% reduction in magnetic material per unit volume due to coating. The percentage of reduction in magnetic material per unit volume determined using TGA/DTA [Figs $10(\mathrm{a}, \mathrm{b}), 11$ $(a, b)]$ shows the correlation as mentioned in the Table No 1, which may be attributed to the reduction in magnetization due to the binding of the surface atoms of ferrite structure with the coating material. The TGA/DTA analysis also indicate the amount of coating in the same range.

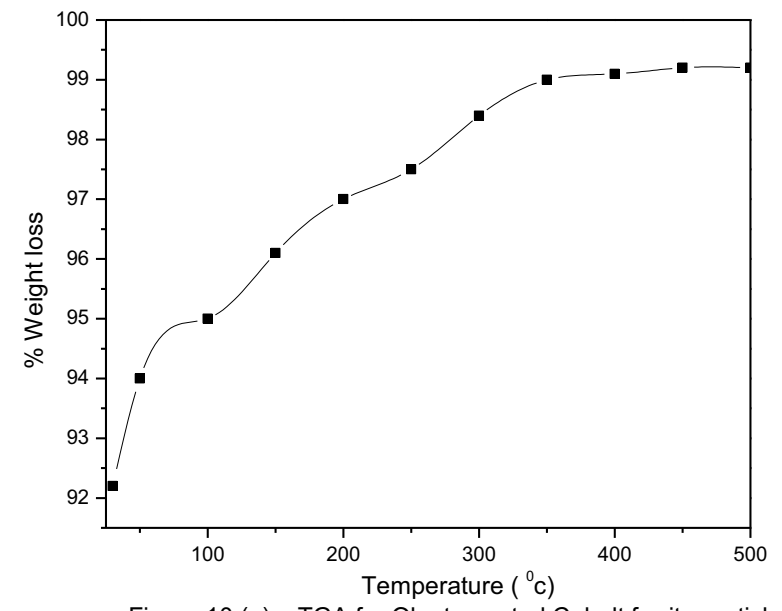

Figure.10 (a). TGA for Oleate coated Cobalt ferrite particles



Figure.10 (b). DTA for Oleate coated Cobalt ferrite particles

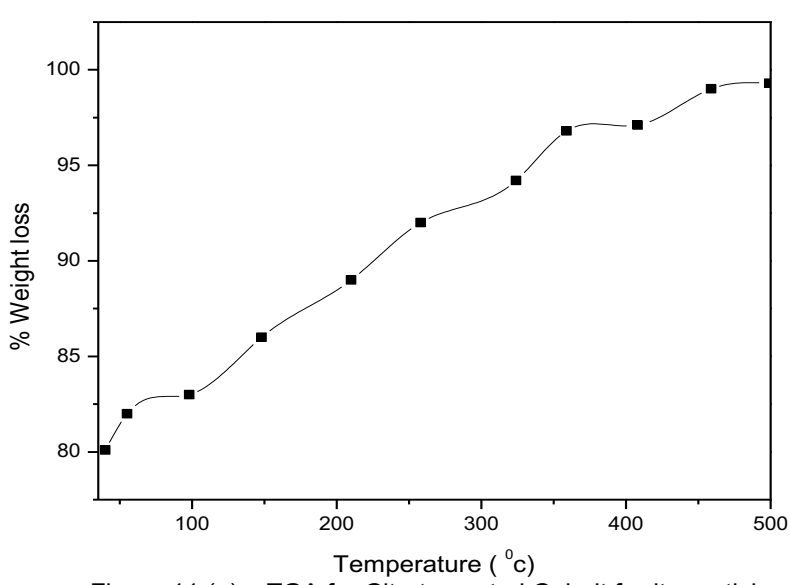

Figure.11 (a). TGA for Citrate coated Cobalt ferrite particles



Figure.11 (b). DTA for Citrate coated Cobalt ferrite particles

Table1 Magnetic measurements for Oleate and Citrate coated Cobalt ferrite.

\begin{tabular}{|l|l|l|l|l|l|}
\hline Sl.N & $\begin{array}{l}\text { Partic } \\
\text { le }\end{array}$ & $\begin{array}{l}\text { Partic } \\
\text { le } \\
\text { size }\end{array}$ & $\begin{array}{l}\text { Saturation } \\
\text { Magnetizat } \\
\text { ion }\end{array}$ & $\begin{array}{l}\text { \% of } \\
\text { material on magnetic } \\
\text { particles }\end{array}$ \\
\cline { 3 - 5 } & & $\begin{array}{l}\text { Obtained } \\
\text { using } \\
\text { magnetizat } \\
\text { ion data }\end{array}$ & $\begin{array}{l}\text { Obtain } \\
\text { ed } \\
\text { using } \\
\text { DTA } \\
\text { analysi } \\
\text { s }\end{array}$ \\
\hline 1 & $\begin{array}{l}\text { Cobal } \\
\text { t } \\
\text { Ferrit } \\
\text { e }\end{array}$ & 45 & 16.8 & - & - \\
\hline 2 & $\begin{array}{l}\text { Oleat } \\
\text { e } \\
\text { coate } \\
\mathrm{d}\end{array}$ & 70 & 9.8 & $64 \%$ & $66 \%$ \\
\hline 3 & $\begin{array}{l}\text { Citrat } \\
\text { e } \\
\text { coate } \\
\mathrm{d}\end{array}$ & 84 & 9.0 & $77 \%$ & $75 \%$ \\
\hline
\end{tabular}




\section{Conclusions}

The chemical co-precipitation method at controlled pH and temperature results into smaller particle size. The thickness of coating material is also found to be dependant upon the temperature and the $\mathrm{pH}$ at which the process is carried out. The magnetic properties obtained in the process are found to be suitable from application point of view.

\section{References}

1. C.Beregmann, D. Muller-Schulte, J.Oster, L.a'Brassard,A.S.Lubbe., J. of Magn. Magn. Mater, 194,(1999) 45-52.

2. Akira Ito, Eri Hibino, Hiroyuki Honda, Kenichiro Hata, Hideaki Kagamic, Minoru Uedad, Takeshi Kobayashi., Biochemical Engineering Journal, (20), (2004) 119-125.

3. A. Petri-Finka, M. Chastellaina, L. JuilleratJeanneretb, A. Ferraria, H. Hofmanna., Biomaterials, 26 ,(2005) 2685-2694.

4. Lubbe AS, Bergemann C, Riess H, Schriever F, Reichardt P, Possinger K, Matthias M, Dorken B, Herrmann F, Gurtler R, Hohenberger P, Haas N, Sohr R, Sander B, Lemke AJ, Ohlendorf D, Huhnt W, Huhn D., Cancer Res, 56 (1996)468693.
5. M.H. Khedr , A.A. Omar, S.A. Abdel-Moaty, Colloids and Surfaces A: Physicochem. Eng. Aspects, 281, (2006) 8-14.

6. DongEn Zhang, XiaoJun Zhang, XiaoMin Ni, JiMei Song, HuaGui Zheng, J. of Magn. Magn. Mater, 305, (2006) 68-70.

7. Tobias Neuberger, Bernhard Schopf, Heinrich Hofmann, Margarete Hofmann, Brigette Von Rechenberg. J. of Magn. Magn. Mater, 293(2005)483-496.

8. K. Maaza, Arif Mumtaza, S.K. Hasanaina, Abdullah Ceylan, Journal of Magnetism and Magnetic Materials 308 (2007) 289-295.

9. H. Yin, H.P. Too, G.M. Chow., Biomaterials, 26, (2005) 5818-5826.

10. N. Millot, S. Le Gallet, D. Aymesa, F. Bernard , Y. Grin., Journal of the European Ceramic Society, 27, (2007) 921-926.

11. R D Waldron, Phys. Rev., 87 (1952)290.

12. S.C. Watawe, B.D.Sutar and B.D. Sarwade., J. of inorganic materials, 3, (2001) 819.

13. Advanced Organic Spectroscopy, 5th edition, Pavia, Lapmann, Kriz.

14. A.S.Eggmann, A.K.Petford-Long, P.J.Dobson, J.Wiggins, T.Bromwick, R.Dunin- Borkowski, T.Kasama., J. of Magn. Magn. Mater, 301(2),(2006)336-342. 